\title{
Correlation and prediction of solubility of hydrogen in alkenes and its dissolution properties
}

\author{
Mohammad Jamali $^{1}$ Amir Abbas Izadpanah ${ }^{1}$ (D) Masoud Mofarahi ${ }^{1,2}$
}

Received: 14 September 2020 / Accepted: 18 November 2020 / Published online: 4 January 2021

(c) The Author(s) 2021

\begin{abstract}
In this work, solubility of hydrogen in some alkenes was investigated at different temperatures and pressures. Solubility values were calculated using the Peng-Robinson equation of state. Binary interaction parameters were calculated using fitting the equation of state on experimental data, Group contribution method and Moysan correlations and total average absolute deviation for these methods was 3.90, 17.60 and 13.62, respectively. Because hydrogen solubility in Alkenes is low, Henry's law for these solutions were investigated, too. Results of calculation showed with increasing temperature, Henry's constant was decreased. The temperature dependency of Henry's constants of hydrogen in ethylene and propylene was higher than to other alkenes. In addition, using Van't Hoff equation, the thermodynamic parameters for dissolution of hydrogen in various alkenes were calculated. Results indicated that the dissolution of hydrogen was spontaneous and endothermic. The total average of dissolution enthalpy $\left(\Delta H^{\circ}\right)$ and Gibbs free energy $\left(\Delta G^{\circ}\right)$ for these systems was $3.867 \mathrm{~kJ} / \mathrm{mol}$ and $6.361 \mathrm{~kJ} / \mathrm{mol}$, respectively. But dissolution of hydrogen in almost of alkenes was not an entropy-driven process.
\end{abstract}

Keywords PR EoS $\cdot$ Solubility $\cdot$ Henry's constant $\cdot$ Thermodynamic properties $\cdot$ Hydrogen $\cdot$ Alkene

\section{Introduction}

Study on the solubility of gases in a variety of hydrocarbons and their dissolution properties is important. Hydrogen is one of these gases which its solubility in hydrocarbons is one of the important parameters in designing, optimizing and interpreting kinetic reactions that are needed in various industrial processes and the commissioning of related equipment. Hydrogenation reactors in petrochemical complexes, are one of the equipment that hydrogen solubility in the input feed can affect the quality of products. Therefore, reliable estimation of hydrogen solubility in alkenes is needed, which results in more precise information gained for designing and optimizing hydrogenation reactors and amount of hydrogen consumed in a unit. Sagara et al. [21, 22], Vasileva

Amir Abbas Izadpanah

izadpanah@pgu.ac.ir

1 Department of Chemical Engineering, Faculty of Petroleum, Gas and Petrochemical Engineering, Persian Gulf University, Bushehr 75169, Iran

2 Department of Chemical and Biomolecular Engineering, Yonsei University, 50 Yonsei-ro, Seodaemun-gu, Seoul 120-749, Republic of Korea et al. [32], Sokolov and Polyakov [28], and Xie et al. [33] experimentally investigated the hydrogen-olefin systems. Baird et al. [5] studied the solubility of hydrogen in shale oil experimentally. The results showed that the solubility of hydrogen is very small due to phenolic polar compounds in shale oil. Given that prediction and calculation of solubility and phase equilibrium with cubic equations of state for hydrogen-hydrocarbon systems is good, these systems are modeled more with cubic equations of state. Ferrando and Ungerer [7] modeled phase equilibria of hydrogen-1-hexene and hydrogen-1-octene systems by PR [20] equation of state using interaction parameter that presented by Moysan et al. [12]. Also Qian et al. [19] studied the phase equilibria of hydrogen-ethylene, hydrogen-propylene and hydrogen1-hexene systems using the PR equation with binary interaction parameter obtained by group contribution method [10]. Aguilar-Cisneros et al. [1,2] investigated the solubility of hydrogen in heavy oil cuts by combining the PR and UNIFAC model (Universal Quasi-Chemical Functional Group Activity Coefficients), with an overall error near to $15 \%$. Torres et al. [30] presented augmented Grayson-Streed model for predicting hydrogen solubility in normal alkanes and aromatics by studying the hydrogen solubility in these hydrocarbons using the Grayson-Streed [29] model. The 
proposed model improves the predicted values of hydrogen solubility in normal alkanes and aromatics. Also, Nasery et al. [14] developed a model based on adaptive neuro fuzzy inference system (ANFIS) to predict hydrogen solubility in oil cut, based on available data from open literature. The average absolute deviation and coefficient of determination $\left(R^{2}\right)$ of model were $3.4 \%$ and 0.99 , respectively, which indicates good accuracy and correlation of the model. The results showed that the model could predict experimental data with acceptable accuracy.

Solubility of gases in a solution decreases significantly by increasing or decreasing pressure that applied on the solution and according Henry's law, the amount of gas that is dissolved at a constant temperature in a certain amount of liquid is directly proportional to the partial pressure of the gas above the solution. Due to the fact that dilute solutions follow the Henry's law, usually the Henry's constant of these systems is calculated. Nakahara and Hirata [13], Orentlicher and Prausnitz [15] studied Henry's constant of hydrogen in alkenes such as ethylene and propylene, Angelo and Francesco [6] studied Henry's constant of hydrogen in alcohols and Park et al. [17] studied Henry's constant of hydrogen in heavy paraffins. Recently, Trinh et al. [31] have studied Henry's constant of hydrogen in compounds containing alkanes, alcohols, aldehydes, carboxylic acids, esters and ethers.

The thermodynamic properties of dissolution, such as enthalpy, entropy, and Gibbs free energy, are important in terms of theoretically and practically. Using these quantities, one can predict and calculate behavior of the system at different conditions without laboratory data. The calculation of thermodynamic dissolution properties is carried out using the Van't Hoff equation. Anthony et al. [4] calculated enthalpy and entropy of dissolved various gases (hydrogen, nitrogen, argon, etc.) in ionic liquid [bmim] [PF6] using the Van't Hoff equation. In other work, they examined the enthalpy and entropy of water dissolution in a variety of ionic liquids by this equation [3]. Recently, Liu et al. [11] investigated the thermodynamic properties of the dissolution of various types of gases, including hydrogen, in the ionic liquid [emim] [Tf2N] using the Van't Hoff equation. Also Shakeel et al. [23-26] using the Van't Hoff equation, calculated the thermodynamic properties of dissolved solids in liquids.

In this work, the solubility of hydrogen in olefins that exist in a variety of petrochemical streams is considered and will be investigated. The studied olefins in this work are ethylene, propylene, 1-butene, 1-hexene, 1-heptene and 1-octene. A thermodynamic model was developed for investigating the solubility of hydrogen in these olefins. In this model, the PR equation of state is used, and the interaction parameter between hydrogen and olefins is obtained by fitting the experimental data of hydrogen solubility in olefins. Interaction parameters are also calculated using methods such as Moysan and GCM and are compared with the interaction parameter obtained by fitting. Using methods such as Moysan and GCM to calculate the interaction parameter in equation of state, it is possible to predict the hydrogen solubility in olefins. Henry's constant of hydrogen is also rarely investigated in the previous work. In this work, Henry's constant of hydrogen is calculated and evaluated in all systems studied with the PR equation of state. Finally, the thermodynamic properties of dissolution such as enthalpy (heat of solution), entropy and Gibbs free energy of dissolution are calculated for these systems because these properties are necessary to describe these solution and design of processes. These properties are also obtained for the first time and are not observed in previous work.

\section{Thermodynamic modeling}

The Peng-Robinson equation of state is written as follows [20]:

$P=\frac{R T}{v-b}-\frac{a}{v(v+b)+b(v-b)}$.

With

$a=a_{c} \alpha(T)$,

$b=0.0777960739 \frac{R T_{c}}{P_{c}}$,

$a_{c}=0.457235529 \frac{R^{2} T_{c}^{2}}{P_{c}}$,

$\alpha(T)=\left[1+m\left(1-\sqrt{\frac{T}{T_{c}}}\right)\right]^{2}$,

where $P, R, T, v, T_{c}, P_{c}$ and $\omega$ are pressure, universal gas constant, temperature, molar volume, critical temperature, critical pressure and acentric factor, respectively. The parameter $m$ is calculated according the value of the acentric factor:

$\omega<0.49: m=0.37464+1.54226 \omega-0.426992 \omega^{2}$,

$\omega>0.49: m=0.379642+1.48503 \omega-0.164423 \omega^{2}+0.016666 \omega^{3}$.

$a$ and $b$ for the mixtures are:

$a=\sum_{i=1}^{N} \sum_{j=1}^{N} z_{i} z_{j} \sqrt{a_{i} a_{j}}\left[1-k_{i j}(T)\right]$, 
$b=\sum_{i=1}^{N} z_{i} b_{i}$

where in Eqs. (8) and (9), $z_{i}, z_{j}$ and $k_{i j}$ are mole fraction of component $i$ and $j$ in mixture and binary interaction parameter, respectively. Binary interaction parameters were calculated using three methods:

- Fitting

- Group contribution method

- Moysan correlation

In the first method, binary interaction parameter was obtained by fitting experimental hydrogen solubility by equation of state. The binary interaction parameter between hydrogen and the alkenes has been evaluated by minimizing the following objective function:

O.F. $=\left(\frac{1}{N}\right) \sum_{i=1}^{N} \operatorname{Abs}\left(\frac{P_{\exp _{i}}-P_{\mathrm{cal}_{i}}}{P_{\exp _{i}}}\right)$,

where $N$ is the number of points used, $P_{\exp }$ is the experimental pressure from literatures and $P_{\text {cal }}$ is the calculated pressure with the PR78 equation of state that Binary interaction parameters were calculated using fitting the equation of state on experimental data, group contribution method and Moysan correlation. Bubble point calculations have been used to calculate the total pressure in these systems.

In the second method, the GCM [10] was used to calculate the binary interaction parameter:

\section{Thermodynamic parameters for dissolution of hydrogen}

The thermodynamic parameters for dissolution of hydrogen in various alkenes were expressed (or measured) in terms of dissolution enthalpy $\left(\Delta H^{\circ}\right)$, Gibbs free energy $\left(\Delta G^{\circ}\right)$, and dissolution entropy $\left(\Delta S^{\circ}\right)$. The $\Delta H^{\circ}$ values for dissolution behavior of hydrogen in each alkene were determined using Van't Hoff equation [23-26]. The $\Delta H^{\circ}$ was calculated using Eq. (13):

$\Delta H^{\circ}=-R \frac{\partial \ln (x)}{\partial\left(\frac{1}{T}-\frac{1}{T_{\text {mean }}}\right)}$.

where $R$ is the universal gas constant $(8.314 \mathrm{~J} / \mathrm{mol} \mathrm{K})$, and $T_{\text {mean }}$, is the mean of the experimental temperatures. The $\Delta H^{\circ}$ values were obtained from the slope of the plot of $\ln (x)$ versus $\left(\frac{1}{T}-\frac{1}{T_{\text {mean }}}\right)$. The $\Delta G^{\circ}$ for the dissolution of hydrogen can be calculated as:

$\Delta G^{\circ}=-R T *$ intercept.

In which the intercept was obtained from the plot of $\ln (x)$ versus $\left(\frac{1}{T}-\frac{1}{T_{\text {mean }}}\right)$. Finally, from these evaluated $\Delta H^{\circ}$ and $\Delta G^{\circ}$ values, the $\Delta S^{\circ}$ of dissolution were obtained using Eq. (15):

$\Delta S^{\circ}=\frac{\Delta H^{\circ}-\Delta G^{\circ}}{T_{\text {mean }}}$.

$k_{i j}(T)=\frac{-\frac{1}{2} \sum_{k=1}^{N_{g}} \sum_{l=1}^{N_{g}}\left(\alpha_{i k}-\alpha_{j k}\right)\left(\alpha_{i l}-\alpha_{j l}\right) A_{k l}\left(\frac{298.15}{T}\right)^{\left(\frac{B_{k l}}{A_{k l}}-1\right)}-\left(\frac{\sqrt{a_{i}(T)}}{b_{i}}-\frac{\sqrt{a_{j}(T)}}{b_{j}}\right)}{2 \frac{\sqrt{a_{i}(T) a_{j}(T)}}{b_{i} b_{j}}}$,

where in Eq. (11), $N_{g}$ is the number of different groups defined by the method and $a_{i k}$ is the fraction of molecule $i$ occupied by group $k$. $A_{k l}=A_{l k}$ and $B_{k l}=B_{l k}$ (where $k$ and $l$ are two different groups) are constant parameters that were determined by Qian et al. [19].

The third method for calculating the binary interaction parameter between hydrogen and alkenes for this equation of state is the proposed equation by Moysan et al. [12]:

$k_{H_{2}, j}=1+\frac{0.0417\left(T_{r, H_{2}}-1\right)-1}{\sqrt{\alpha_{H_{2}}}}$.

In Eq. (12), $T_{r, H 2}$ is reduced temperature of hydrogen and $\alpha_{H 2}$ is defined by Eq. (5).

\section{Results and discussion}

\section{Correlation and prediction of hydrogen solubility}

Table 1 presents the critical properties of the compounds used. The Binary interaction parameter is obtained at each temperature by fitting the equation of state on experimental data, group contribution method (GCM) and Moysan correlation. The binary interaction parameters are given in Table 2.

The average absolute deviation (AAD) between experimental data and correlation/prediction of $\mathrm{H}_{2}$ solubility in the different alkenes is given in Table 3. The results show that using the PR equation with $k_{i j}$ obtained from the fitting of data, has lower average error in comparison with the $k_{i j}$ 
Table 1 Critical properties and acentric factors

\begin{tabular}{llllllll}
\hline & Hydrogen & Ethylene & Propylene & 1-Butene & 1-Heptene & 1-Hexene & 1-Octene \\
\hline Tc (K) & 33.19 & 282.3 & 365.6 & 420.0 & 537.29 & 504.0 & 567.0 \\
Pc (bar) & 13.13 & 50.40 & 46.65 & 40.43 & 28.30 & 31.40 & 26.80 \\
$\omega$ & -0.216 & 0.087 & 0.140 & 0.191 & 0.331 & 0.280 & 0.393 \\
Ref. & Smith et al. [27] & Smith et al. [27] & Smith et al. [27] & Smith et al. [27] & Smith et al. [27] & Smith et al. [27] & Poling et al. [18] \\
\hline
\end{tabular}

Table 2 Binary interaction parameter and calculated Henry's constant values

\begin{tabular}{|c|c|c|c|c|c|c|c|c|}
\hline \multirow[t]{2}{*}{ Systems } & \multirow[t]{2}{*}{ Temp (K) } & \multirow[t]{2}{*}{$x\left(\mathrm{H}_{2}\right.$ molar fraction $)$} & \multirow[t]{2}{*}{ Pressure (bar) } & \multicolumn{3}{|l|}{$k_{i j}$} & \multirow[t]{2}{*}{$H_{1,2}(\mathrm{bar})^{*}$} & \multirow[t]{2}{*}{ Ref.** } \\
\hline & & & & Fitting & Moysan & GCM & & \\
\hline \multirow[t]{5}{*}{ Hydrogen/ethylene } & 123.15 & $0.0053-0.0146$ & $20.3-81.1$ & 0.1010 & 0.0886 & -0.0218 & 3769.0 & Sagara et al. [21] \\
\hline & 148.15 & $0.0074-0.0266$ & $20.3-81.1$ & 0.1265 & 0.1160 & 0.0059 & 2641.6 & Sagara et al. [21] \\
\hline & 173.15 & $0.0087-0.0361$ & $20.3-81.1$ & 0.1690 & 0.1441 & 0.0322 & 1989.6 & Sagara et al. [21] \\
\hline & 198.15 & $0.0100-0.0489$ & $20.3-81.1$ & 0.1898 & 0.1727 & 0.0573 & 1431.1 & Sagara et al. [21] \\
\hline & 223.15 & $0.0084-0.0603$ & $20.3-81.1$ & 0.2315 & 0.2019 & 0.0816 & 913.95 & Sagara et al. [21] \\
\hline \multirow[t]{4}{*}{ Hydrogen/propylene } & 173.20 & $0.0054-0.0200$ & $20.3-81.1$ & 0.2200 & 0.1441 & 0.2078 & 3775.0 & Sagara et al. [22] \\
\hline & 198.20 & $0.0060-0.0239$ & $20.3-81.1$ & 0.3200 & 0.1728 & 0.1824 & 3331.5 & Sagara et al. [22] \\
\hline & 223.20 & $0.0086-0.0275$ & $20.3-81.1$ & 0.3649 & 0.2019 & 0.1695 & 2534.0 & Sagara et al. [22] \\
\hline & 248.20 & $0.0098-0.0499$ & $20.3-81.1$ & 0.3220 & 0.2316 & 0.1588 & 1763.5 & Sagara et al. [22] \\
\hline \multirow[t]{3}{*}{ Hydrogen/1-butene } & 253.20 & $0.0390-0.2100$ & $50.0-300.0$ & 0.0055 & 0.2376 & 0.1482 & 1137.3 & Vasileva et al. [32] \\
\hline & 314.69 & $0.0420-0.2360$ & $50.0-300.0$ & 0.2341 & 0.3123 & 0.1519 & 964.18 & Vasileva et al. [32] \\
\hline & 356.78 & $0.0470-0.1980$ & $50.0-200.0$ & 0.3877 & 0.3647 & 0.1591 & 727.95 & Vasileva et al. [32] \\
\hline \multirow[t]{4}{*}{ Hydrogen/1-hexene } & 333.20 & $0.0400-0.2280$ & $39.2-294.2$ & 0.2003 & 0.3352 & 0.2033 & 940.95 & Sokolov and Polyakov [28] \\
\hline & 393.20 & $0.1090-0.2490$ & $100.0-250.7$ & 0.3557 & 0.4107 & 0.2247 & 719.13 & Sokolov and Polyakov [28] \\
\hline & 403.20 & $0.0410-0.3030$ & $39.2-294.2$ & 0.3552 & 0.4234 & 0.2285 & 681.69 & Sokolov and Polyakov [28] \\
\hline & 453.20 & $0.1400-0.3460$ & $100.0-250.7$ & 0.5084 & 0.4878 & 0.2479 & 487.28 & Sokolov and Polyakov [28] \\
\hline \multirow[t]{2}{*}{ Hydrogen/1-heptene } & 333.20 & $0.0280-0.2010$ & $39.2-294.2$ & 0.3444 & 0.3352 & 0.2230 & 1152.7 & Sokolov and Polyakov [28] \\
\hline & 403.20 & $0.0401-0.2650$ & $39.2-294.2$ & 0.3907 & 0.4234 & 0.2521 & 747.88 & Sokolov and Polyakov [28] \\
\hline \multirow[t]{5}{*}{ Hydrogen/1-octene } & 313.15 & $0.0080-0.0600$ & $9.3-73.6$ & 0.1471 & 0.3104 & 0.2092 & 1142.6 & Xie et al. [33] \\
\hline & 328.20 & $0.0240-0.1860$ & $39.2-294.2$ & 0.3095 & 0.3290 & 0.2193 & 1248.9 & Sokolov and Polyakov [28] \\
\hline & 333.15 & $0.0080-0.0590$ & $9.4-70.0$ & 0.2227 & 0.3422 & 0.2226 & 1123.1 & Xie et al. [33] \\
\hline & 393.20 & $0.0380-0.2430$ & $40.5-304.0$ & 0.3505 & 0.4107 & 0.2617 & 873.42 & Sokolov and Polyakov [28] \\
\hline & 463.20 & $0.0490-0.3180$ & $40.5-304.0$ & 0.4827 & 0.5008 & 0.3057 & 591.36 & Sokolov and Polyakov [28] \\
\hline
\end{tabular}

*Calculated Henry's constant by fugacity coefficients using PR equation of state with fitting binary interaction coefficient

**References of experimental data $(\mathrm{P}-\mathrm{T}-\mathrm{x})$

obtained from the Moysan and GCM method, which was predictable.

Comparison of the modeling results using the $k_{i j}$ obtained from the Moysan and GCM method shows that the average error associated with the Moysan method is less than the GCM. Of course, this result was unexpected because the GCM method is a newer method than Moysan and is expected to have better results. The reason for the weak results of the GCM method may be the optimal parameters of the model $\left(A_{k l}\right.$ and $\left.B_{k l}\right)$ and the components used to optimize the parameters of the GCM model. For example, optimization of the parameters of the GCM model was done with cyclic and high-carbon number hydrocarbons. But in the present work, hydrocarbons with a low carbon number are modeled. So that average error between experimental hydrogen solubility and modeling results by GCM method for systems hydrogen + ethylene or propylene was high.

Another reason that could lead to errors in the results of the prediction of general models such as GCM and Moysan is the temperature range in which the parameters of these models is fitted in this range. If the fitting of the parameters was performed at high temperature and these parameters used at low temperatures, this can be caused the high error and the weakness of the model results (for example, the prediction results of the hydrogen + 1-butene system at $253.2 \mathrm{~K}$ using the Moysan $k_{i j}$ ). 
Table 3 Average absolute deviation (AAD) for solubility of hydrogen in alkenes

\begin{tabular}{|c|c|c|c|c|c|c|}
\hline \multirow[t]{2}{*}{ Systems } & \multirow[t]{2}{*}{$T(\mathrm{~K})$} & \multirow[t]{2}{*}{$x\left(\mathrm{H}_{2}\right.$ molar fraction $)$} & \multirow[t]{2}{*}{ Pressure (bar) } & \multicolumn{3}{|l|}{$(\mathrm{AAD}) \%$} \\
\hline & & & & $\mathrm{PR} 78+k_{i j}$ fitting & $\begin{array}{l}\text { PR78 }+k_{i j} \\
\text { Moysan }\end{array}$ & $\mathrm{PR} 78+k_{i j} \mathrm{GCM}$ \\
\hline \multirow[t]{5}{*}{ Hydrogen/ethylene } & 123.15 & $0.0053-0.0146$ & $20.3-81.1$ & 7.86 & 10.24 & 43.39 \\
\hline & 148.15 & $0.0074-0.0266$ & $20.3-81.1$ & 5.34 & 7.28 & 35.71 \\
\hline & 173.15 & $0.0087-0.0361$ & $20.3-81.1$ & 5.22 & 9.97 & 32.01 \\
\hline & 198.15 & $0.0100-0.0489$ & $20.3-81.1$ & 4.98 & 7.44 & 24.76 \\
\hline & 223.15 & $0.0084-0.0603$ & $20.3-81.1$ & 1.09 & 3.53 & 15.65 \\
\hline \multirow[t]{4}{*}{ Hydrogen/propylene } & 173.20 & $0.0054-0.0200$ & $20.3-81.1$ & 4.71 & 20.69 & 4.90 \\
\hline & 198.20 & $0.0060-0.0239$ & $20.3-81.1$ & 5.12 & 28.62 & 26.51 \\
\hline & 223.20 & $0.0086-0.0275$ & $20.3-81.1$ & 5.08 & 24.03 & 28.55 \\
\hline & 248.20 & $0.0098-0.0499$ & $20.3-81.1$ & 4.17 & 24.39 & 16.18 \\
\hline \multirow[t]{3}{*}{ Hydrogen/1-butene } & 253.20 & $0.0390-0.2100$ & $50.0-300.0$ & 1.62 & 62.38 & 33.24 \\
\hline & 314.69 & $0.0420-0.2360$ & $50.0-300.0$ & 2.41 & 11.23 & 10.44 \\
\hline & 356.78 & $0.0470-0.1980$ & $50.0-200.0$ & 1.44 & 2.71 & 17.83 \\
\hline \multirow[t]{4}{*}{ Hydrogen/1-hexene } & 333.20 & $0.0400-0.2280$ & $39.2-294.2$ & 3.92 & 18.45 & 3.94 \\
\hline & 393.20 & $0.0280-0.2010$ & $100.0-250.7$ & 1.82 & 4.90 & 12.45 \\
\hline & 403.20 & $0.0410-0.3030$ & $39.2-294.2$ & 3.81 & 12.01 & 7.19 \\
\hline & 453.20 & $0.0410-0.2650$ & $100.0-250.7$ & 4.31 & 7.26 & 18.67 \\
\hline \multirow[t]{2}{*}{ Hydrogen/1-heptene } & 333.20 & $0.0280-0.2010$ & $39.2-294.2$ & 6.34 & 6.60 & 15.34 \\
\hline & 403.20 & $0.0410-0.2650$ & $39.2-294.2$ & 2.69 & 3.15 & 13.86 \\
\hline \multirow[t]{5}{*}{ Hydrogen/1-octene } & 313.15 & $0.0080-0.0600$ & $9.3-73.6$ & 1.38 & 17.50 & 6.69 \\
\hline & 328.20 & $0.0240-0.1860$ & $39.2-294.2$ & 8.67 & 9.05 & 15.36 \\
\hline & 333.15 & $0.0080-0.0590$ & $9.4-70.0$ & 1.41 & 12.57 & 1.42 \\
\hline & 393.20 & $0.0380-0.2430$ & $40.5-304.0$ & 3.57 & 4.88 & 11.45 \\
\hline & 463.20 & $0.0490-0.3180$ & $40.5-304.0$ & 4.68 & 5.17 & 12.02 \\
\hline Total AAD $\%$ & & & & 3.98 & 13.65 & 17.72 \\
\hline
\end{tabular}

Figure 1 shows solubility of hydrogen in alkenes using PR EoS with $k_{i j}$ by Fitting, GCM and Moysan correlations.

\section{Henry's law}

Henry's law is used to describe the low solubility of hydrogen in a variety of alkene solvents. Based on definition, the Henry's constant of a solute in a solvent, $H_{1,2}$ is given as:

$H_{1,2}=\lim _{x_{1} \rightarrow 0}\left(\frac{f_{1}^{l}}{x_{1}}\right)=\lim _{x_{1} \rightarrow 0}\left(\varphi_{1} P\right)$,

where $f_{1}^{l}, x_{1}$, and $\varphi_{1}$ are the fugacity, mole fraction and fugacity coefficient of hydrogen in the liquid phase, respectively. The Henry's constant was calculated using the PR equation and binary interaction parameter derived from the fitting of experimental solubility data. Accordingly, at each temperature, pressure and mole fraction of hydrogen in liquid phase, fugacity coefficient of hydrogen in liquid phase was calculated. The calculated fugacity coefficient was multiplied by system pressure. The obtained values were plotted in terms of hydrogen mole fraction in the liquid phase. Draw the best passing line through the points, and the intersection of this line with the vertical axis gives the Henry's constant at that temperature. Figure 2 shows how to use this method to calculate the Henry's constant of hydrogen in ethylene at 123.15 K. The Henry's constant of hydrogen in some alkenes are given in Table 2. Also, Fig. 3 presents the temperature dependency of these Henry's constants.

According to Fig. 3, Henry's constant of hydrogen decrease with increasing temperature, which show that with increasing temperature, the solubility of hydrogen in alkenes increases (see Fig. 1; Tables 2, 3, columns 2, 3). Temperature dependency of Henry's constant of hydrogen in ethylene and propylene is higher than that of other alkenes, which indicates that the temperature has a greater effect on the solubility of hydrogen in ethylene and propylene.

The calculated Henry's constant values of hydrogen in ethylene in this work and the values calculated by Nakahara and Hirata (BWR equation of state, [13], were compared to experimental data [13], and Orentlicher and Prausnitz [15] at temperature 173 and $199 \mathrm{~K}$. also, that comparison was made for calculated Henry's constant of hydrogen in propylene at temperature $200 \mathrm{~K}$. The Comparison showed that average 

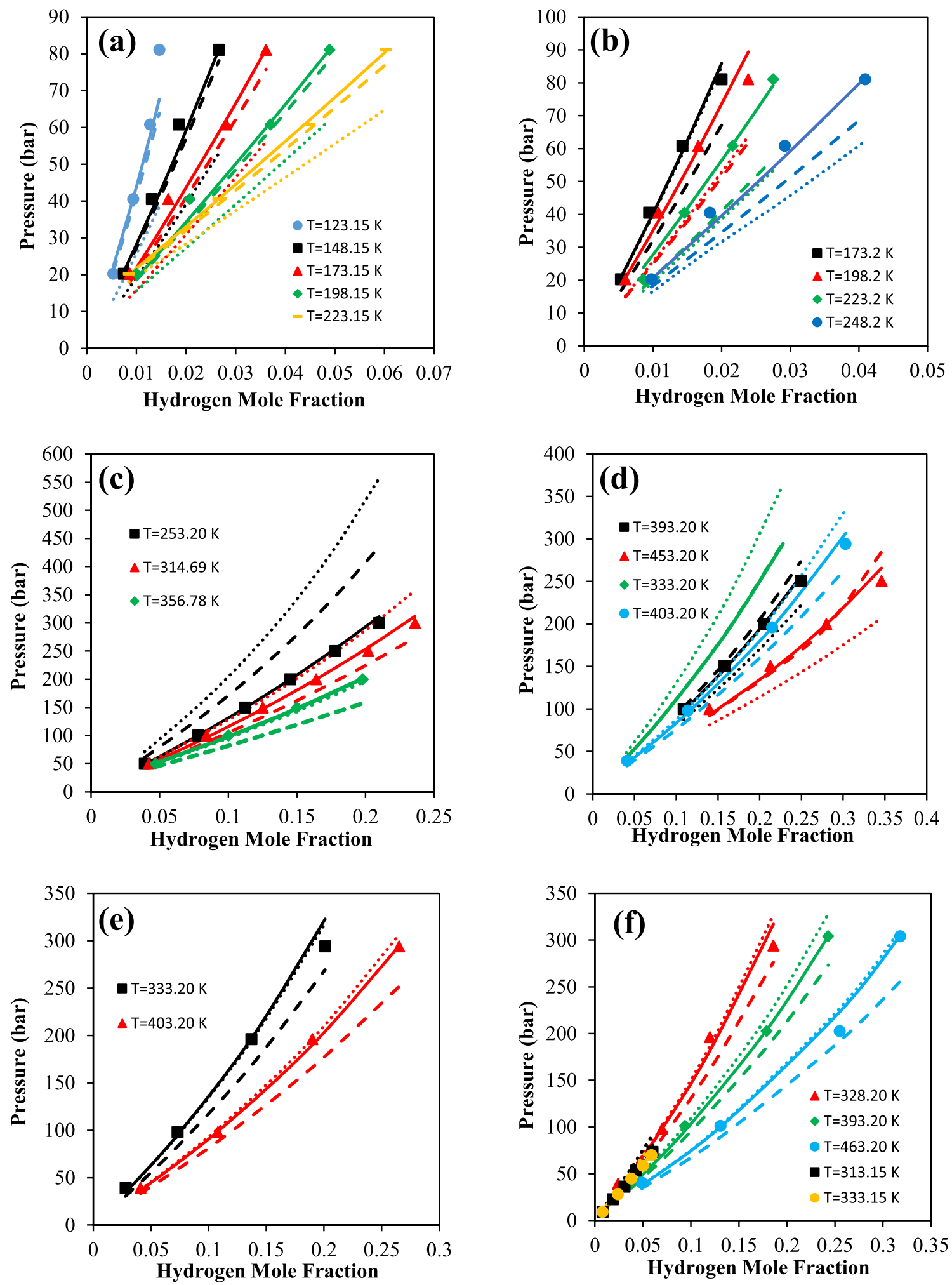

Fig. 1 Correlation and prediction of solubility of hydrogen in alkenes using PR EoS with $k_{i j}$ by fitting, GCM and Moysan correlations. Solid points (O): experimental data. Solid line $(-)$ : solubility correlation using PR EoS with $k_{i j}$ by fitting, dashed line (---): solubility prediction using PR EoS with $k_{i j}$ by GCM, dotted line (.....):

solubility prediction using PR EoS with $k_{i j}$ by Moysan correlation. Systems: a hydrogen + ethylene, b hydrogen + propylene ,c hydrogen +1-butene, d hydrogen +1-hexene, e hydrogen +1-heptene, $\mathbf{f}$ hydrogen +1 -octene 


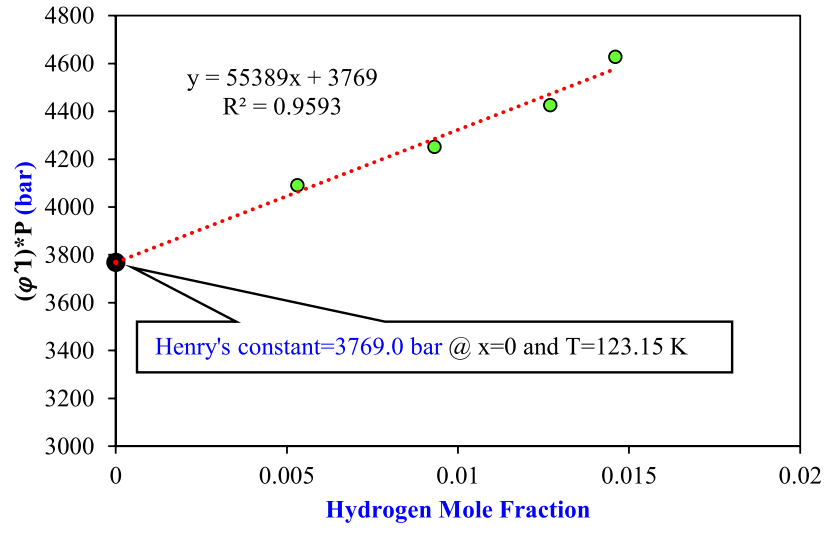

Fig. 2 Evaluation of Henry's constant of hydrogen in ethylene at $T=123.15 \mathrm{~K}$

absolute deviation (AAD\%) between experimental data and calculated Henry's constant in this work was $9.80 \%$ and AAD\% between experimental data and calculated Henry's constant by BWR equation of state [13], was $8.85 \%$. These comparisons show that the equation of state and method used in this work to obtain the Henry's constant of hydrogen in the alkenes is reliable and the errors associated to this model are in the level and size of previous work. These results were shown in Table 4.

\section{Thermodynamic parameters for dissolution of hydrogen in Alkenes}

The values of thermodynamic parameters for dissolution of hydrogen in Alkenes are listed in Table 4 . The $\Delta H^{\circ}$ values for the dissolution of hydrogen were positive for all solvents studied. The positive values of $\Delta H^{\circ}$ indicated endothermic dissolution of hydrogen. The $\Delta G^{\circ}$ values for the dissolution of hydrogen were also observed to be positive for all the solvents studied. Positive values of $\Delta G^{\circ}$ indicating that the dissolution of hydrogen was spontaneous and the positive values of $\Delta G^{\circ}$ in Alkene solvents were possible due to strong molecular interactions between hydrogen-solvent molecules in comparison with weak molecular interactions between hydrogen-hydrogen and solvent-solvent molecules. As can be seen from Table 5, all dissolution entropy of hydrogen in ethylene, propylene, 1-butene, and 1-hexene at $100 \mathrm{bar}$, and 1 -octene at 45.5 and 101.3 bar are negative that indicate the dissolution of hydrogen are not an entropy-driven process. Other value of $\Delta S^{\circ}$ of hydrogen in alkene (1-hexene at $P=150$ bar, $P=200$ bar, $P=250$ bar and 1 -octene at
$P=202.7$ bar, $P=304.0$ bar) are positive, that indicate the dissolution of hydrogen are an entropy-driven process.

Also according to Table 5 (4) the values of $\Delta H^{\circ}$ and $\Delta G^{\circ}$ for the dissolution of hydrogen in alkenes were very low, which indicated that relatively low energy is required for the solubilization of hydrogen in alkenes.

In this work, the thermodynamic properties for dissolution of nitrogen, helium, argon and methane in alkenes have been studied, too (Table 6). Comparison of the values of the thermodynamic properties of hydrogen, nitrogen, helium, argon and methane shows that the enthalpy of light gases in alkenes is very low. Also, the positive values of enthalpy of hydrogen and helium in alkenes indicates an increase solubility by increasing the temperature and negative values of enthalpy of nitrogen, argon and methane in alkenes indicates a decrease in solubility with increasing temperature.

\section{Conclusion}

The solubility of hydrogen in ethylene, propylene, 1-butene, 1-hexene, 1-heptene and 1-octene was investigated. The PR equation was used to correlate and predict the hydrogen solubility in alkenes. Binary interaction parameter was obtained by fitting the equation of state on experimental data, group contribution method and Moysan correlations. The results showed PR EoS with fitting binary interaction parameter had lowest absolute average error than Moysan and group contribution method, respectively. Because most dilute solutions follow Henry's law, Henry's constant was calculated for all studying systems using PR equations of state with fitting binary interaction parameter. With increasing temperature, Henry's constant of hydrogen in alkenes decreased and hydrogen solubility increased in these systems. Also Henry's constants of hydrogen in ethylene and propylene were more than in other alkenes. These binary interaction parameters and Henry's constant can be used in simulation software to simulate industrial processes containing hydrogen and alkenes (petrochemical industries). In addition, Thermodynamic analysis indicated endothermic and spontaneous dissolution behavior of hydrogen in the studied alkene solvents. But results show the dissolution of hydrogen in some of alkenes is an entropy-driven process, such as 1-hexene and 1-octene. Also some recommendations for future work are: (a) using statistical associating fluid theory (SAFT) family equation of state to model system containing hydrogen, (b) ternary systems and mixtures containing hydrogen will be investigated, (c) another olefin such as branched and cycloolefin will be investigated. 


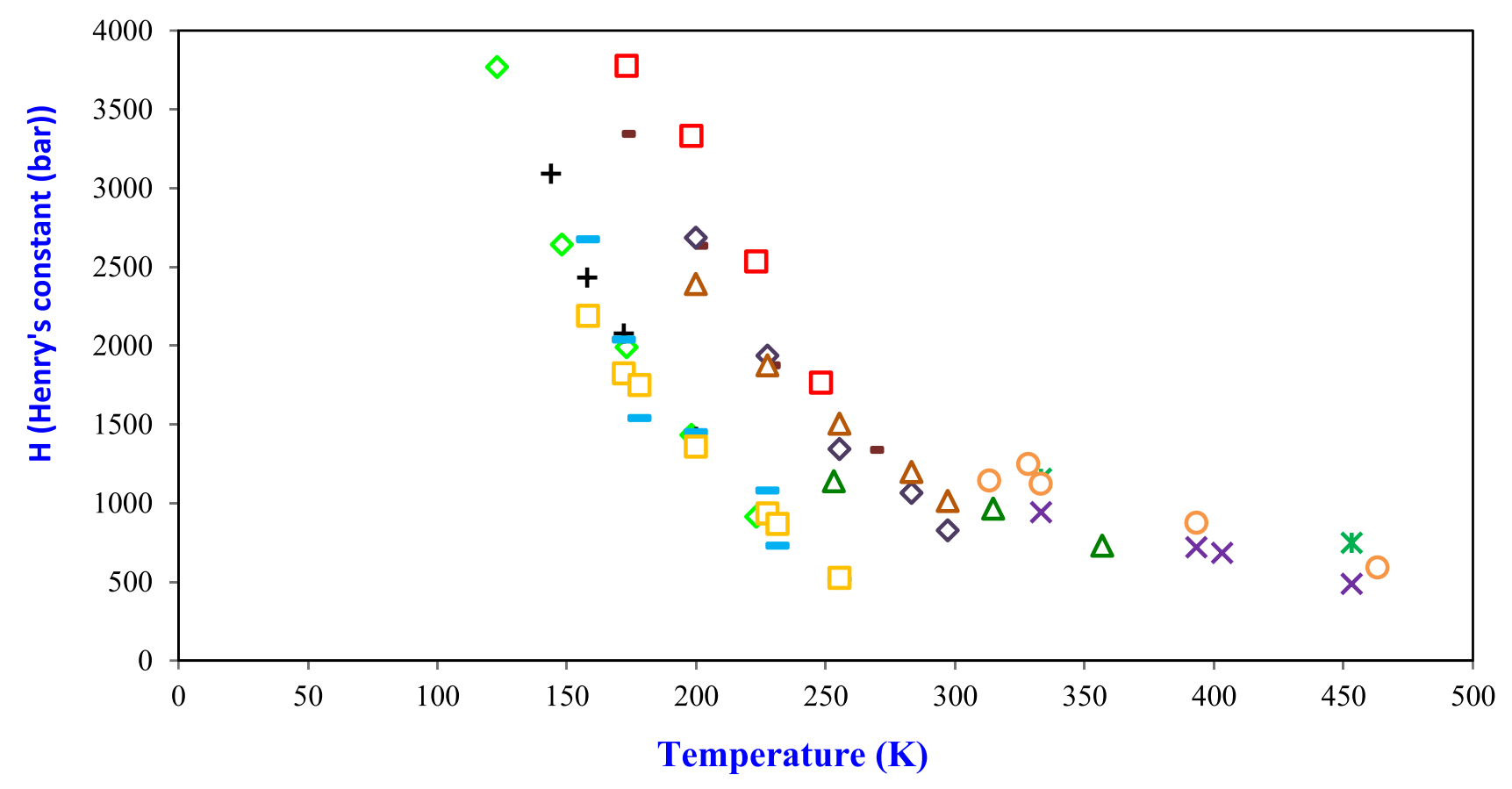

- H (Hydrogen,Ethylene)-This work

口H (Hydrogen,Propene)-This work

$\Delta \mathrm{H}$ (Hydrogen,1-butene)-This work

×H (Hydrogen,1-Hexene)-This work

- $\mathrm{H}$ (Hydrogen, 1-Heptene)-This work

- H (Hydrogen, 1-Octene)-This work

- H (Hydrogen,Ethylene) from M. Orentlicher and J. M. Prausnit (Orentlicher and Prausnitz 1964)

-H (Hydrogen,Propylene) from M. Orentlicher and J. M. Prausnit (Orentlicher and Prausnitz 1964)

- Experimental H (Hydrogen,Ethylene) from Tomoko Nakahara and Mitsuho Hirata (Nakahara and Hirata 1969)

- Experimental H (Hydrogen,Propylene) from Tomoko Nakahara and Mitsuho Hirata (Nakahara and Hirata 1969)

$\square \mathrm{H}$ (Hydrogen,Ethylene) from Tomoko Nakahara and Mitsuho Hirata by BWR EoS (Nakahara and Hirata 1969)

$\Delta \mathrm{H}$ (Hydrogen,Propylene) from Tomoko Nakahara and Mitsuho Hirata by BWR EoS (Nakahara and Hirata 1969)

Fig. 3 Experimental and calculated Henry's constant of hydrogen in some alkenes studied in this work vs. temperature 
Table 4 Experimental Henry's constant data and calculated by equation of states

\begin{tabular}{|c|c|c|c|c|c|c|c|}
\hline & \multirow[t]{2}{*}{$T(\mathrm{~K})$} & \multirow{2}{*}{$\begin{array}{l}\text { Experimental } \\
\text { Henry's constant } \\
\text { by Nakahara and } \\
\text { Hirata } \\
\text { Nakahara and } \\
\text { Hirata [13] }\end{array}$} & \multirow{2}{*}{$\begin{array}{l}\text { Experimental } \\
\text { Henry's constant } \\
\text { by Orentlicher } \\
\text { and Prausnitz } \\
\text { Orentlicher and } \\
\text { Prausnitz [15] }\end{array}$} & \multirow{2}{*}{$\begin{array}{l}\text { Calculated } \\
\text { Henry's constant } \\
\text { by BWR* EOS } \\
\text { Nakahara and } \\
\text { Hirata [13] }\end{array}$} & \multirow{2}{*}{$\begin{array}{l}\text { Calculated } \\
\text { Henry's constant } \\
\text { by PR EOS } \\
\text { This work }\end{array}$} & \multicolumn{2}{|l|}{$\mathrm{AAD} \%$} \\
\hline & & & & & & $\begin{array}{l}\text { This work and } \\
\text { experimental } \\
\text { Henry's constant } \\
\text { data }\end{array}$ & $\begin{array}{l}\text { BWR and exper- } \\
\text { imental Henry's } \\
\text { constant data }\end{array}$ \\
\hline \multirow{2}{*}{$\begin{array}{l}\text { Hydrogen/eth- } \\
\text { ylene }\end{array}$} & 173 & 2037 & 2070 & 1824 & 1990 & 9.80 & 8.85 \\
\hline & 199 & 1449 & 1419 & 1358 & 1431 & & \\
\hline $\begin{array}{l}\text { Hydrogen/pro- } \\
\text { pylene }\end{array}$ & 200 & 2685 & 2634 & 2391 & 3331 & & \\
\hline
\end{tabular}

*Benedict-Webb-Rubin equation of state

Table 5 Thermodynamic parameters of hydrogen dissolution at different pressures and the mean of the experimental temperatures $\left(T_{\text {mean }}\right)$

\begin{tabular}{|c|c|c|c|c|c|}
\hline Solvent & $T_{\text {mean }}(\mathrm{K})$ & $P$ (bar) & $\Delta H^{\circ}(\mathrm{KJ} / \mathrm{mol})$ & $\Delta G^{\circ}(\mathrm{KJ} / \mathrm{mol})$ & $\Delta S^{\circ}(\mathrm{J} / \mathrm{mol} \mathrm{K})$ \\
\hline \multirow[t]{4}{*}{ Ethylene } & \multirow[t]{4}{*}{173.15} & 20.27 & 1.229 & 6.933 & -32.94 \\
\hline & & 40.53 & 2.314 & 5.836 & -20.34 \\
\hline & & 60.80 & 2.950 & 5.145 & -12.68 \\
\hline & & 81.06 & 3.202 & 4.751 & -8.947 \\
\hline \multirow[t]{4}{*}{ Propylene } & \multirow[t]{4}{*}{210.70} & 20.27 & 3.998 & 8.660 & -22.13 \\
\hline & & 40.53 & 3.208 & 7.570 & -20.70 \\
\hline & & 60.80 & 3.356 & 6.664 & -15.70 \\
\hline & & 81.06 & 3.170 & 6.265 & -14.68 \\
\hline \multirow[t]{4}{*}{ 1-Butene } & \multirow[t]{4}{*}{308.20} & 50.00 & 1.270 & 8.065 & -22.04 \\
\hline & & 100.0 & 1.652 & 6.228 & -14.85 \\
\hline & & 150.0 & 1.979 & 5.226 & -10.54 \\
\hline & & 200.00 & 2.120 & 4.534 & -7.834 \\
\hline \multirow[t]{4}{*}{ 1-Hexene } & \multirow[t]{4}{*}{395.70} & 100.0 & 4.951 & 7.175 & -5.623 \\
\hline & & 150.0 & 5.997 & 5.982 & 0.040 \\
\hline & & 200.0 & 5.670 & 5.060 & 1.542 \\
\hline & & 250.0 & 6.198 & 4.455 & 4.405 \\
\hline \multirow[t]{4}{*}{ 1-Octene } & \multirow[t]{4}{*}{394.87} & 40.50 & 5.583 & 10.72 & -13.01 \\
\hline & & 101.3 & 6.841 & 7.700 & -2.176 \\
\hline & & 202.7 & 6.715 & 5.528 & 3.005 \\
\hline & & 304.0 & 4.938 & 4.538 & 1.013 \\
\hline
\end{tabular}

Table 6 Thermodynamic dissolution parameters of nitrogen, helium, argon and methane in some alkenes at different pressures, and the mean of the experimental temperatures $\left(T_{\text {mean }}\right)$

\begin{tabular}{llllllll}
\hline Solute & Solvent & $T_{\text {mean }}(\mathrm{K})$ & $P($ bar $)$ & $\Delta H^{\circ}(\mathrm{KJ} / \mathrm{mol})$ & $\Delta G^{\circ}(\mathrm{KJ} / \mathrm{mol})$ & $\Delta S^{\circ}(\mathrm{J} / \mathrm{mol} \mathrm{K})$ & Ref.* \\
\hline $\mathrm{N}_{2}$ & Ethylene & 153.09 & 26.00 & -3.013 & 2.784 & -37.87 & Gasem et al. [9] \\
& & 154.50 & 16.00 & -2.963 & 3.627 & -42.66 & Gasem et al. [9] \\
& & 128.43 & 10.00 & -2.888 & 3.039 & -46.15 & Gasem et al. [9] \\
$\mathrm{He}$ & Ethylene & 178.67 & 60.00 & 6.839 & 7.819 & -5.482 & Garber and Ziegler [8] \\
$\mathrm{He}$ & Propylene & 213.56 & 60.00 & 7.658 & 9.136 & -6.922 & Garber and Ziegler [8] \\
$\mathrm{Ar}$ & Propylene & 135.00 & 12.00 & -13.78 & 2.214 & -118.5 & Orobinsky et al. [16] \\
$\mathrm{CH}_{4}$ & Ethylene & 223.20 & 40.53 & -11.80 & 1.947 & -61.57 & Sagara et al. [21] \\
\hline
\end{tabular}

*References of experimental data $(\mathrm{P}-\mathrm{T}-\mathrm{x}$ data) 
Open Access This article is licensed under a Creative Commons Attribution 4.0 International License, which permits use, sharing, adaptation, distribution and reproduction in any medium or format, as long as you give appropriate credit to the original author(s) and the source, provide a link to the Creative Commons licence, and indicate if changes were made. The images or other third party material in this article are included in the article's Creative Commons licence, unless indicated otherwise in a credit line to the material. If material is not included in the article's Creative Commons licence and your intended use is not permitted by statutory regulation or exceeds the permitted use, you will need to obtain permission directly from the copyright holder. To view a copy of this licence, visit http://creativecommons.org/licenses/by/4.0/.

\section{References}

1. Aguilar-Cisneros H, Carreón-Calderón B, Uribe-Vargas V, Domínguez-Esquivel JM, Ramirez-de-Santiago M (2018) Predictive method of hydrogen solubility in heavy petroleum fractions using EOS/G E and group contributions methods. Fuel 224:619-627

2. Aguilar-Cisneros H, Uribe-Vargas V, Carreón-Calderón B, Domínguez-Esquivel JM, Ramirez-de-Santiago M (2017) Hydrogen solubility in heavy undefined petroleum fractions using group contributions methods. Oil Gas Sci Technol Revue d'IFP Energies nouvelles 72(1):2

3. Anthony JL, Maginn EJ, Brennecke JF (2001) Solution thermodynamics of imidazolium-based ionic liquids and water. J Phys Chem B 105(44):10942-10949

4. Anthony JL, Maginn EJ, Brennecke JF (2002) Solubilities and thermodynamic properties of gases in the ionic liquid 1-n-butyl3-methylimidazolium hexafluorophosphate. J Phys Chem B 106(29):7315-7320

5. Baird ZS, Uusi-Kyyny P, Oja V, Alopaeus V (2017) Hydrogen solubility of shale oil containing polar phenolic compounds. Ind Eng Chem Res 56(30):8738-8747

6. d'Angelo JVH, Francesconi AZ (2001) Gas- liquid solubility of hydrogen in $n$-alcohols $(n=1-4)$ at pressures from 3.6 MPa to $10 \mathrm{MPa}$ and temperatures from $298.15 \mathrm{~K}$ to $525.15 \mathrm{~K}$. J Chem Eng Data 46(3):671-674

7. Ferrando N, Ungerer P (2007) Hydrogen/hydrocarbon phase equilibrium modelling with a cubic equation of state and a Monte Carlo method. Fluid Phase Equilib 254(1):211-223

8. Garber JD, Ziegler WT (1979) Gas-liquid equilibrium for the helium-ethylene and helium-propylene systems below $260 \mathrm{~K}$ and $120 \mathrm{~atm}$. J Chem Eng Data 24(4):330-338

9. Gasem KM, Hiza M, Kidnay A (1981) Phase behavior in the nitrogen+ ethylene system from 120 to $200 \mathrm{~K}$. Fluid Phase Equilib 6(3-4):181-189

10. Jaubert J-N, Mutelet F (2004) VLE predictions with the PengRobinson equation of state and temperature dependent kij calculated through a group contribution method. Fluid Phase Equilib 224(2):285-304

11. Liu H, Dai S, Jiang D-E (2014) Solubility of gases in a common ionic liquid from molecular dynamics based free energy calculations. J Phys Chem B 118(10):2719-2725

12. Moysan J, Huron M, Paradowski H, Vidal J (1983) Prediction of the solubility of hydrogen in hydrocarbon solvents through cubic equations of state. Chem Eng Sci 38(7):1085-1092

13. Nakahara T, Hirata M (1969) The prediction of henry"s constants for hydrogen-hydrocarbon systems. J Chem Eng Jpn 2(2):137-142

14. Nasery S, Barati-Harooni A, Tatar A, Najafi-Marghmaleki A, Mohammadi AH (2016) Accurate prediction of solubility of hydrogen in heavy oil fractions. J Mol Liq 222:933-943
15. Orentlicher M, Prausnitz J (1964) Thermodynamics of hydrogen solubility in cryogenic solvents at high pressures. Chem Eng Sci 19(10):775-782

16. Orobinsky N, Blagoy YP, Semyannikova E (1968) Liquid-vapor phase equilibrium of the propylene-argon and propylene-krypton systems at high temperatures. Ukr Phys J 13:263-268

17. Park J, Robinson RLJ, Gasem KA (1995) Solubilities of hydrogen in heavy normal paraffins at temperatures from 323.2 to $423.2 \mathrm{~K}$ and pressures to 17.4 MPa. J Chem Eng Data 40(1):241-244

18. Poling BE, Prausnitz JM, O'connell JP (2001) The properties of gases and liquids. Mcgraw-hill, New York

19. Qian J-W, Jaubert J-N, Privat R (2013) Prediction of the phase behavior of alkene-containing binary systems with the PPR78 model. Fluid Phase Equilib 354:212-235

20. Robinson DB, Peng D-Y (1978) The characterization of the heptanes and heavier fractions for the GPA Peng-Robinson programs, Gas Processors Association

21. Sagara H, Arai Y, Saito S (1972) Vapor-liquid equilibria of binary and ternary systems containing hydrogen and light hydrocarbons. J Chem Eng Jpn 5(4):339-348

22. Sagara H, Mihara S, Arai Y, Saito S (1975) Vapor-liquid equilibria and Henry's constants for ternary systems containing hydrogen and light hydrocarbons. J Chem Eng Jpn 8(2):98-104

23. Shakeel F, Bhat MA, Haq N (2014) Solubility of (2 Z)-Ncyclohexyl-2-(3-hydroxybenzylidine) hydrazine carbothioamide in different pure solvents at (298.15 to 338.15) K. J Chem Eng Data 59(6):2126-2130

24. Shakeel F, Bhat MA, Haq N, Fathi-Azarbayjani A, Jouyban A (2017) Solubility and thermodynamic parameters of a novel anticancer drug (DHP-5) in polyethylene glycol 400+ water mixtures. J Mol Liq 229:241-245

25. Shakeel F, Haq N, Radwan AA, Alanazi FK, Alsarra IA (2016) Solubility and thermodynamic analysis of $\mathrm{N}^{\prime}-(1-(\mathrm{N}-($ methyl $)$ benzylaminomethyl)-2-oxoindolin-3-ylidene)-2-(benzyloxy) benzohydrazide in different neat solvents at different temperatures. J Mol Liq 220:108-112

26. Shakeel F, Iqbal M, Ezzeldin E, Haq N (2015) Thermodynamics of solubility of ibrutinib in ethanol+ water cosolvent mixtures at different temperatures. J Mol Liq 209:461-464

27. Smith JM, Van Ness HC, Abbott MM (2003) Introduction to chemical engineering thermodynamics. McGraw-Hill, New York

28. Sokolov V, Polyakov A (1977) Solubility of H 2 in n-decane, n-tetradecane, 1-hexane, 1-octene, isopropyl benzene, 1-methyl naftalene and decalin. Zh Prikl Khim 50:1403-1405

29. Streed GG (1963) Vapor-liquid equilibria for high temperatur, high pressure hydrogen-hydrocarbon systems. In: 6th World Petroleum Congress, World Petroleum Congress

30. Torres R, De Hemptinne J-C, Machin I (2013) Improving the modeling of hydrogen solubility in heavy oil cuts using an augmented Grayson Streed (AGS) approach. Oil Gas Sci Technol Revue d'IFP Energies nouvelles 68(2):217-233

31. Trinh T-K-H, de Hemptinne J-C, Lugo R, Ferrando N, Passarello J-P (2015) Hydrogen solubility in hydrocarbon and oxygenated organic compounds. J Chem Eng Data 61(1):19-34

32. Vasileva I, Naumova A, Polyakov A, Tyvina T, Fokina V (1986) Phase and volume-dependent relationships in hydrogen-1-hexene, hydrogen-1-octene, and hydrogen-c15-c18 olefin systems. J Appl Chem USSR 59(6):1180-1183

33. Xie Z, Snavely WK, Scurto AM, Subramaniam B (2009) Solubilities of $\mathrm{CO}$ and $\mathrm{H} 2$ in neat and $\mathrm{CO} 2$-expanded hydroformylation reaction mixtures containing 1-Octene and nonanal up to 353.15 $\mathrm{K}$ and $9 \mathrm{MPa}$. J Chem Eng Data 54(5):1633-1642

Publisher's Note Springer Nature remains neutral with regard to jurisdictional claims in published maps and institutional affiliations. 